Portland State University

PDXScholar

1978

\title{
The Threat Index and two forms of resistance to the concept of death
}

Henry E. Miller Jr.

Portland State University

Follow this and additional works at: https://pdxscholar.library.pdx.edu/open_access_etds

Part of the Psychology Commons

Let us know how access to this document benefits you.

\section{Recommended Citation}

Miller, Henry E. Jr., "The Threat Index and two forms of resistance to the concept of death" (1978). Dissertations and Theses. Paper 2846.

https://doi.org/10.15760/etd.2840

This Thesis is brought to you for free and open access. It has been accepted for inclusion in Dissertations and Theses by an authorized administrator of PDXScholar. Please contact us if we can make this document more accessible: pdxscholar@pdx.edu. 
AN ABSTRACT OF THE THESIS OF Henry E. Miller Jr. for the Master of Science in Psychology presented May 15, 1978.

Title: The Threat Index and Two Forms of Resistance to the Concept of Death.

APPROVED BY MEMBERS OF THE THESIS COMMITTEE:
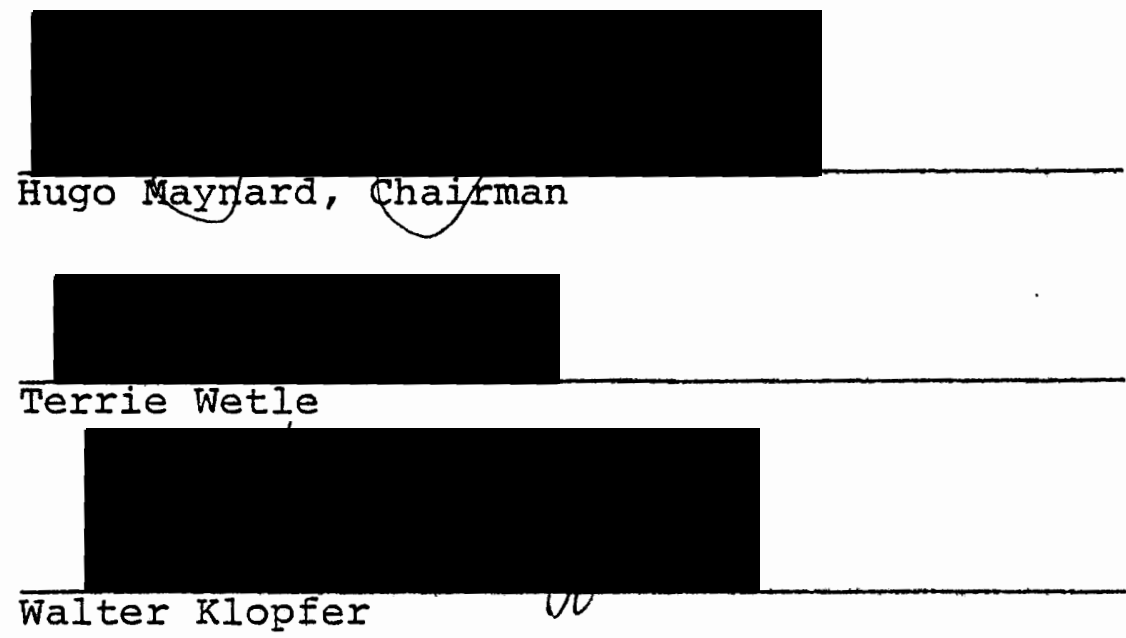

Many investigators of death attitudes have emphasized the iimitation of self-report measures of the fear of death in that responses are often unreal and highly questionable due to defenses and ego maneuvers. The Self-Administered Threat Index. (SATI) introduced by Rainey and Epting (1977) appears to meet most criticisms of other investigators. The present study was a partial replication of the Golding, et al. (1966) study with the SATI replacing the Sarnoff Fear of Death Scale. Forty-six introductory 
psychology students, both males and females, performed a tachistoscopic recognition task, completed the SATI and the Semantic Differential and were administered a brief structured interview.

The tachistoscopic recognition task was flashing death words and neutral words at individually determined speeds to each $\underline{S}$. The death words and neutral words were matched for length and frequency in written English. The words were tree, dead, green, grave, growth, corpse, marriage, and cemetery. The SATI consisted of each $\underline{\mathbf{S}}$ associating one side of each of 40 bi-polar constructs with "preferred self", "self", and "your own death". The Semantic Differential consisted of rating five deathrelated words on seven scales.

The predictions were:

1) The mean number of trials to recognize death words will be significantly greater than the mean number of trials to recognize neutral words.

2) SATI scores will correlate positively with the differences between mean trials to recognize death words and mean trials to recognize neutral words.

3) SATI scores will correlate negatively with the standard deviation scores on the evaluative, potency, and activity factors and the seven individual scales on the Semantic Differential.

4) Differences between mean trials to recognize death 
and neutral words will correlate negatively with the standard deviation scores on the evaluative, potency, and activity factors, and the seven individual scales on the Semantic Differential.

Death words did take significantly longer to recognize than neutral words, therefore, hypothesis one was supported. Hypothesis three was also supported in that SATI scores correlated significantly with one factor (evaluative) and with five of the seven individual scales of the Semantic Differential.

Hypothesis two, SATI scores would correlate positively with the difference between mean recognition trials, was not supported. Hypothesis four, the difference between mean recognition trials will correlate negatively with standard deviations of the semantic differential, was not supported. This later finding contradicted the Golding, et al. (1966) study. While death words did take longer to recognize in both studies, the magnitude of the difference between mean trials did not significantly correlate to standard deviation scores of the Semantic Differential in the present study. Suggestions for further research with the tachistoscope are made. 
THE THREAT INDEX AND TWO FORMS OF RESISTANCE

TO THE CONCEPT OF DEATH

by

HENRY E. MILIER JR.

A thesis submitted in partial fulfillment of the requirements for the degree of

\author{
MASTER OF SCIENCE \\ in \\ PSYCHOLOGY
}

Portland State University 
TO THE OFFICE OF GRADUATE STUDIES AND RESEARCH:

The members of the Committee approve the thesis of Henry E. Miller Jr. presented May 15, 1978.
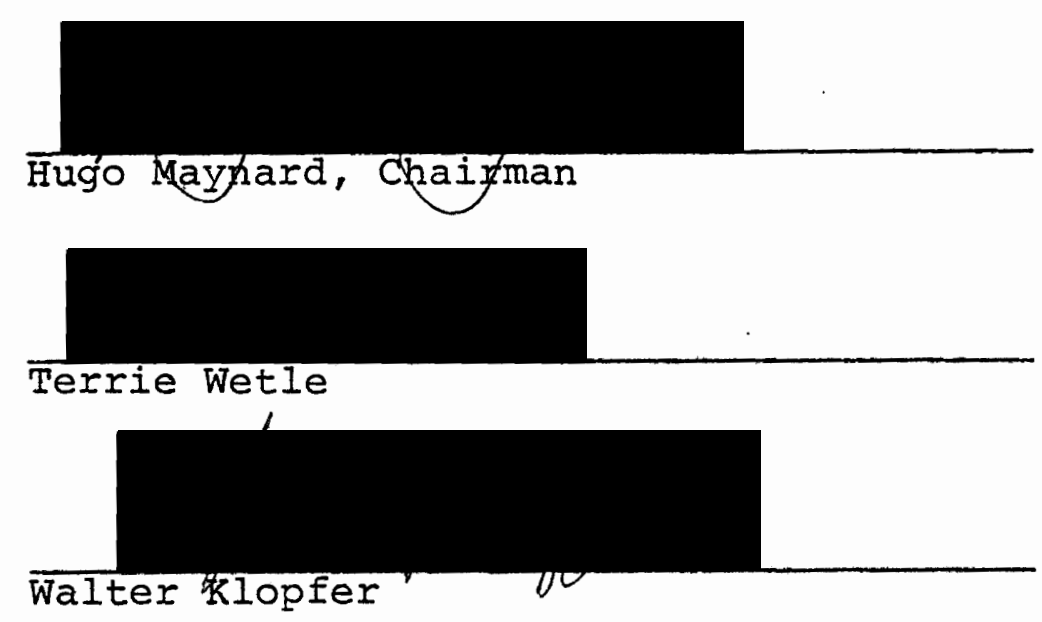

APPROVED:

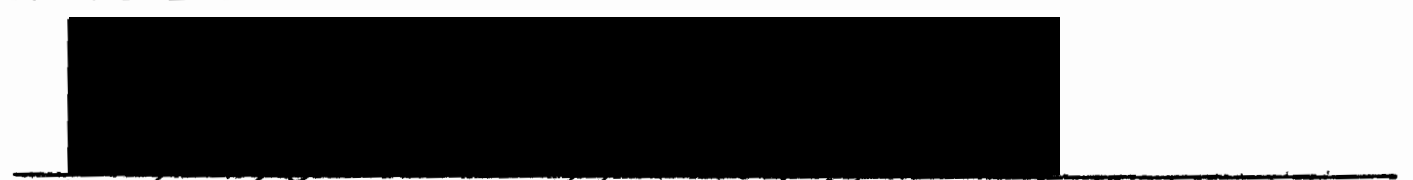

Robert Johes, Head, Department OELPsychology

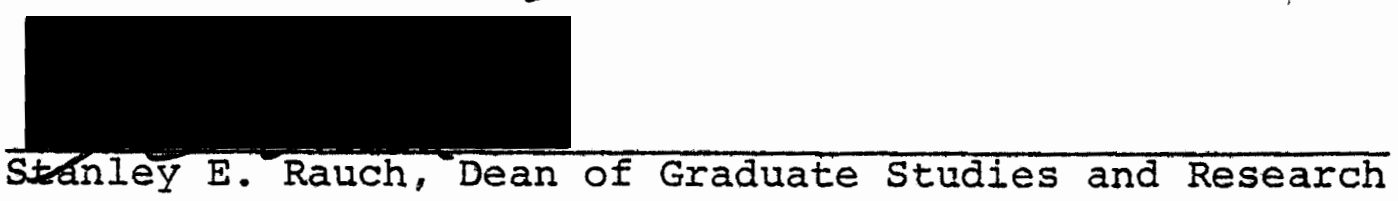




\section{ACKNOWLEDGMENTS}

Many persons have helped and supported me through this research and I am very grateful they were there for me.

First, I would like to express my deep appreciation to Hugo Maynard, who was with me in the early stages of conceptualizing through the final hectic phases of university requirements. The time he spent with me discussing lifedeath issues and the personal history of the alfalfa sprout was invaluable.

I am also very grateful to my other committee members Walter Klopfer and especially Terrie Wetle, who helped me be clear about what I wanted to say.

Barbara stewart is given a special thanks for making statistics humanistic.

One person, whithout whose help this research would have been impossible, is Dr. Franz Epting who promptly returned my correspondence with helpful suggestions and his own unpublished research.

Iast, but not least, are all my friends and lovers. I can only begin to give thanks for their love and support. 


\section{TABLE OF CONTENTS}

PAGE

ACKNOWLEDGEMENTS ....................... ii

IIST OF TABLES........................ $v$

INTRODUCTION........................... I

The Threat Index..................... 4

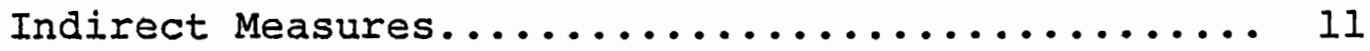

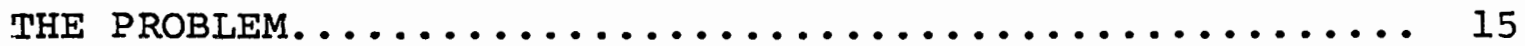

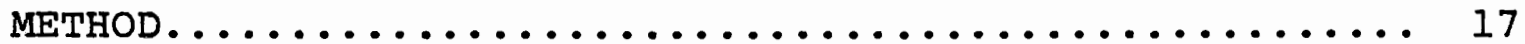

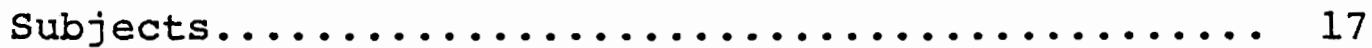

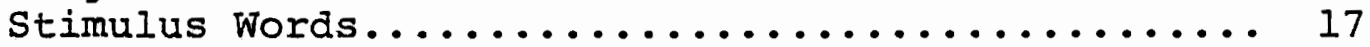

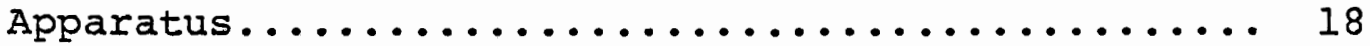

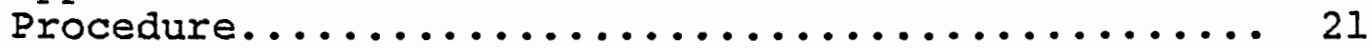

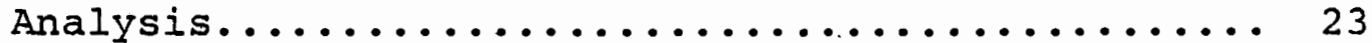

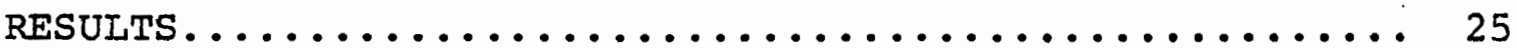

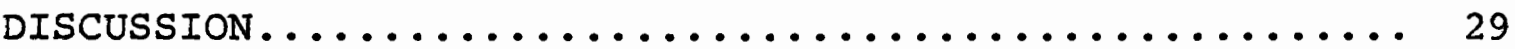

SELECTED BIBLIOGRAPHY..................... 35

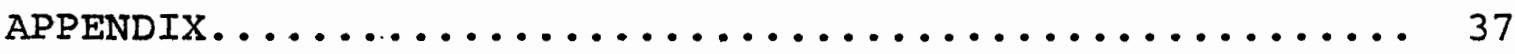

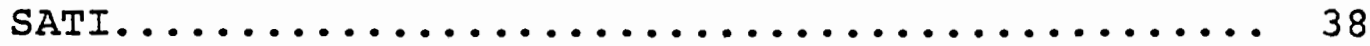

Semantic Differential................... 41

Structured Interview..................... 43

Informed Consent Form.................... 44

Summary of Data by Project............... 45 


\section{LIST OF TABLES}

TABLE

PAGE

I Mean Trials to Recognize Neutral Words and Death Words..................... 26

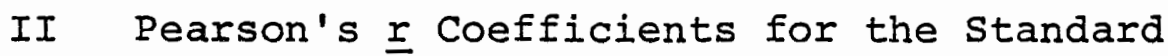

Deviations of the Factors and Scales of the Semantic Differential with Scores on the SATI and with the Mean Difference of Trials to Report Neutral and Death-Related Words.. 27

II Pearson's $\underline{r}$ Coefficients of the Variance Scores of the Factors and Scales of the Semantic Differential with Scores on the SATI and with the Mean Difference of Trialis to Report Neutral and DeathRelated words.................... 33 
INTRODUCTION

Although the roots of psychology have been traced to academic disciplines such as philosophy where the topic of death was prominent (Kastenbaum and Costa, 1977), it has only been in the last twenty years that psychology has considered death as a relevant issue. Kastenbaum and Costa (1977) in the first review of the psychology of death in the Annual Review of Psychology cite several previous major works that sparked little interest and systematic research. Fechner included death as part of developmental psychology in his Little Book of Life After Death (1904), William James (1910) wrote of immortality, G. Stanley Hall (1915) conducted an experimental study of thanataphobia, and Durkheim's work Suicide (1951) all met with little follow up research.

Herman Feifel's book The Meaning of Death (1959) appears to be the first landmark in the new death awareness movement. Since then Farberow and Schneidman (1965) began their research on suicide, Elizabeth Kubler-Ross (1969) wrote On Death and Dying, Omega, Journal of Death and Dying has been published for eight years, and the first attempt to integrate scientific knowledge of death was by Kastenbaum and Aisenberg in The Psychology of Death (1972). 
During the recent movement, the measurement of the fear of death has been a concern. Lester (1967a), in his review of psychometric measures of death fear, concluded that most research in the area produced conflicting results and investigators were unable to agree on the relationship between death attitudes and demographic variables. The lack of agreement may be due to the variety of theoretical conceptualizing (Munnichs, 1961), the variety of samples used (Lester, 1967a; Kastenbaum and Costa, 1977), diverse methodologies and data analysis (Dickstein and Blatt, 1966; Kastenbaum and Aisenberg, 1972; Kastenbaum and Costa, 1977), and the variety of instruments used, including interviews, drawings, forced choice check lists and rating scales, diaries, TAT, sentence completion, free association, and the psychogalvanic skin response (Lester, 1967a).

In addition to the variety of approaches to death attitudes that make comparison among results difficult, several investigators have suggested possible influences on an individual's verbally reported death attitudes. Among these are physiological and psychological nearness to death (Feifel, 1961; Feifel and Branscomb, 1973), recent experience with death (Feifel and Branscomb, 1973; Kastenbaum and Costa, 1977), the meaning of death to the individual such as death of self versus death of another and the act of dying versus the state of death: (Iester, 1967a; Kastenbaum and Aisenberg, 1972; Feifel and Branscomb, 1973; Klug and Boss, 
1976).

Other concerns in devising a death attitude scale are the influence of cultural attitudes or social desirability on reporting death attitudes, the relationship of death anxiety to general anxiety (Kastenbaum and Costa, 1977), and Kastenbaum and Costa's concern that research deal with the orientation toward death as affective-attitudinal or cognitive and the relationship between these two orientations. Lester (1967a) pointed out that conflicting results in previous studies may be due to measuring different levels of death concern. Feifel (196I) and Feifel and Branscomb (1973) also expressed a need for multi-level appraisals. Also, many investigators have emphasized the limitation of self-report measures of the fear of death in that responses are often unreal and highly questionable due to defenses and ego maneuvers (Feifel, 1961; Munnichs, 1961; Lester 1967a; Krieger, et al., 1974; Kastenbaum and Costa, 1977). There is also much concern about the reliability of the self-report measures and lack of validation studies (Feifel, 1961; Kastenbaum and Costa, 1977). Durlak (1973) found no relation between Lester's self-report inventory (1966) and five experimental measures of death concern analyzed in three different ways. He emphasized a need for an adequate measure of death concern.

The development of a device for measuring threat of death has many practical implications. Lester (1967b) 
stated a need to understand the suicidal person's attitudes toward death. Identifying fears of those who work with the dying would benefit both the care giver and the patient. Additionally, the mourning process of survivors is sometimes inhibited by overwhelming anxiety about death.

\section{THE THREAT INDEX}

The Threat Index first reported by Krieger, et al. (1974) is based on Kelly's Theory of Personal Constructs and seems to be the best attempt to date to measure death attitudes. This study by Krieger, et al. (1974) was also cited in the review by Kastenbaum and Costa (1977) as a "model" for research in this area.

The investigators were not satisfied with previous measures because they did not take into account the personal meaning of death for the 'individual. Only the semantic Differential approached doing this but it was limited in that it did not meet the requirement of individuality in that it assumed the scales had a universal meaning. The Semantic Differential also did not reflect structural aspects of subjects' personalities since cognitive dimensions were specified by the experimenters.

Krieger, et al. (1974) report that:

The Psychology of Personal Constructs is a theory of personality which holds that a person's interactions with the world are characterized by his desire to accurately anticipate events in that world through the use of his own constructed interpretations (p. 300). 
...threat is said to be the awareness of an inability to accurately predict events in the world along with the awareness of a need to undertake some degree of systematic change in order to do so ( $p .300)$.

It was therefore hypothesized that death would be threatening to a person in proportion to the amount of systematic reorganization necessary in order to construe death as a personal reality, as part of his "self." Operationalized, threat can be evaluated by determining the reluctance of a person to subsume his present view of himself, the way he prefers to see himself, and the concept of death together as elements under the same poles of a sample of his constructs ( $p .301)$.

The Threat Index, as originally proposed, was a lengthy structured interview. Ten element cards with death relevant situations (e.g., card 2 "You discover that you have leukemia and only a few weeks to live.") were presented in triads to the subject. On one card in each triad was printed "Death". The subject was then asked "How are two alike and different from the third?" The answer was recorded under "construct" pole. Then he was asked "What is the opposite of that?" This answer was recorded under "contrast" pole. These were considered "subordinate constructs." Next, the technique of "Iaddering", proposed by Hinkle (reported in Krieger, et al., 1974) was used to elicit "superordinate" constructs from the responses to the triad procedure. The superordinate constructs were found by Hinkle to be more resistant to change.

Laddering was done by asking the subject if he preferred to see himself as (response to construct pole) or (response to contrast pole).

A check was 
placed in the appropriate "preferred self" box. He was then asked why he prefers to see himself that way as opposed to the other way. If he had trouble answering he was asked "What are the advantages of this one (preferred pole) as opposed to the disadvantages of that one (the non-preferred pole)," and prompted with "I prefer to see myself as (the preferred pole) because..." The response was entered on the second line, an opposite called for, a preference obtained, and the interviewer again asked "Why?" The cycle was continued until he could no longer respond to "Why?" A new triad of cards would then be used. This was continued until 30 constructs were elicited. When this was finished, the experimenter returned to the first construct and asked "Do you, in fact, see yourself as (construct pole) or (contrast pole)?" A check was placed under the appropriate "self" box. The subject was next asked "Do you see Death as (construct pole) or (contrast pole)? This was continued for all 30 constructs. Scoring the Threat Index was simply counting the number of constructs where "preferred self" and "self" appeared together on one pole and "Death" appeared on the opposite pole.

Krieger, et al: (1974) found that the Threat Index correlated ( $\mathrm{p}<.05$ ) with a separate "conceivability of own mortality" item and a separate "fear of death" item $(p<.01)$. Split-half, odd-even reliability was .93 . In the second half of this study the Threat Index was related 
to Lester's (1966) Fear of Death Scale (FDS) and Templer's (1970) Death Anxiety Scale (DAS). The original scoring and a new scoring procedure were used for the Threat Index. Both Threat Indexes correlated .91 ( $p<.01$ ) with each other, both correlated with the FDS, .67 $(p<.01)$ and .73 $(p<\mid .01)$ and neither Threat Index nor the FDS correlated with the DAS above .12. All scales except DAS correlated significantly with conceivability of own mortality and all four lcorrelated with the self report fear of death $(p<.01$ for dil four). Krieger, et al (1974) concluded that either the Threat Index and FDS scale are measuring different constructs from the DAS or they are measuring different aspects of the larger construct of death concern. They cite evidence for the latter interpretation in that all four of the scales correlated positively with self-reported fear of death. Also, males scored higher on both Threat Indexes $(p<1.10)$ and the FDS $(p<.05)$, and the opposite was true for the DAS, with females scoring higher, although not significantly. The experimenters went on to suggest an explanation:

This difference is due perhaps to the fact that Templer's measure is specifically a measure of anxiety and general affective arousal in this area; whereas the other two instruments are dealing with the conceptual understanding of the way death relates to other aspects of their life. Further research is needed to explore this and other interpretations of this difference (p. 308).

This self-administered form of the Threat Index was 
introduced to the literature by Rainey and Epting (1977). They cited a previous study that took the 40 most common bi-polar constructs from Krieger, et al. (1974) and found correlations of .77 with the original, .84 at four week test-retest, and .02 with the Marlowe-Crowne Social Desirability Scale. Rainey and Epting attempted a validation study by administering the short form to two death education classes and two control classes of graduate-level students. The tests were administered at the beginning of the term and at the end of the term. The death classes had significantly lower scores for both pre- and post-tests than the control groups. This did not confirm their hypothesis that the death course would lower death threat scores. Students who enrolled in death education classes already had significantly lower scores than the controls. The death classes' post-test variance increased three fold. Two-thirds of the students in the death classes did in fact decline but the remaining students had much larger increases in their scores. The control classes' pre- and post-tests correlated $r=.874$ over nine weeks and provides a good measure of temporal stability.

In the second part of their study, Rainey and Epting compared persons who pre-planned their funerals or would donate body parts after their death with controls. They found that the pre-planners had significantly lower selfadministered Threat Index scores $(p<.0001)$. 
In an unpublished study by Krieger, et al. (1977) the original Threat Index (TI) and the self-administered Threat Index (SATI) were compared. Part of their study was to validate that the split of the death element on an opposite pole from the elements "self" and "preferred self" was in fact an indicator of threat. They used additional elements of "terrifying" and "comfortable" whose meaning was defined by each individual $\underline{s}$. They administered the TI and SATI, Marlowe-Crowne Social Desirability Scale (MCSDS), and a separate fear of death item (FOD). A second administration of the TI and SATI was given after four weeks. The testretest correlations of the TI and SATI were .816 ( $<<.01)$ and $.896(p<.01)$, respectively, and were not significantly different from each other. The split-half, odd-even reliability for the TI and SATI were .671 and .926, respectively, and boosted to .803 and .962 , respectively, when correlations were corrected for test length. These latter two correlations were different at $p<.01$ level. For the TI the number of splits on the subordinate constructs, the constructs elicited by the stimulus situation cards (see Krieger, et al., 1974), correlated .625 with the number of splits on the superordinate constructs, the constructs elicited by the technique of laddering. This shows that the number of splits elicited from the subordinate and superordinate constructs are similar enough to justify the simple additive scoring of splits. The above correlation also 
provides another measure of internal consistency and is similar to the odd-even, split-half correlation of .67I. The TI and SATI correlated .383 ( $p<.05)$ and .476 $(p<.01)$, respectively, with the FOD item. The difference between correlations was not significant. This shows similarity with self-report of fear but not equivalence. The validity of split meaning threat, was tested by counting splits between "Terrifying" (T) and "Self" and "Preferred Self" (P). For the TI, when S and $P$ were placed on the same pole, T was placed on the opposite pole $79 \%$ of the time $\left(\mathrm{Chi}^{2}=33.6, \mathrm{p}<.01\right)$; for the SATI the same split occurred $84 \%$ of the time $\left(\mathrm{Chi}^{2}=46.2, \mathrm{p}<.01\right)$. The "Comfortable" element was placed on the same pole as $S$ and $\mathrm{P} 94 \%$ of the time for the TI $\left(\mathrm{Chi}^{2}=77.4, \mathrm{p}<.0 \mathrm{I}\right)$ and $95 \%$ of the time for the SATI $\left(\mathrm{Chi}^{2}=81.0, \mathrm{p}<.01\right)$. When the TI was administered in this study some of the original death-related situation cards were replaced with new ones to test the difference. The correlation of splits on constructs elicited by the old and new situations was $.610(p<.01)$. This was also similar to the splithalf reliability coefficient and splits on superordinate and subordinate constructs. Both the TI, SATI, and selfreport fear item were found not correlated with the MCSDS.

In summary the SATI seems to have good reliability and validity, to be independent of social desirability as measured by the Marlowe-Crowne Social Desirability Scale, 
and to be theoretically linked to dimensions of personality.

\section{INDIRECT MEASURES}

Several studies have dealt with the less conscious aspects of death concern and all seem to be in agreement. They have used the psychogalvanic skin response and word association measures to assess death attitudes. Meissner (1958) measured GSR responses for associations to psychoanalytic, death-symbol words and neutral words. He found lower skin resistance to the death-symbol words which were also found to be associated to the "death" concept and not some other vicarious association. He concluded that death symbols elicit a differential emotional response.

Alexander, et al. (1957) measured GSR and response time to death, affective, and basal words in a word association task. They found that subjects had significantly lowered skin resistance $(p<.01)$ and greater response latencies $(p<.01)$ when associating to death words and affective words than when associating to basal words.

Alexander and Adlerstein (1958) using the same procedure described above for children five to sixteen found the same results for the whole group. But when the data were divided into age groups, younger children had less significant GSR responses. Response time differences remained significant $(p<.01)$ for all age groups. They 
also suggest that response time is more sensitive to cultural influences.

Christ (1961) found it took geriatric psychiatric patients longer to respond to death words than to neutral words on a word association task.

Feifel and Branscomb (1973) measured three levels of awareness and death concern and found the dominant conscious response was "repudiation", where $71 \%$ of the sample answered "no" to the question "Are you afraid of your own death?". The dominant fantasy level response was rated "ambivalence", compared to "positive" and "negative". This judgment was made by two raters on responses to "What ideas or pictures come to your mind when you think about your own death?" The third level, "Below-the-level-of-awareness" was measured by a word association test, in which death words had a significantly longer mean reaction time $(p<.01)$ and mean recall time $(\mathrm{p}<.01)$, and by the color-word interference test, where it took SS longer to read death words. Of the 371 Ss only 19 Ss were consistently "fearful" at all levels and 6 Ss were consistently "nonafraid" at all three levels.

Golding, et al. (1966) attempted to relate death anxiety and the resistance on the part of an individual against consciously considering death and ideas associated with it. They claimed that the resistance took two forms. One, the resistance to allowing ideas of death to enter consciousness, was called "perceptual defense." This was 
measured by a tachistoscopic recognition task in which the experimenters counted the number of trials required to recognize death words as opposed to neutral words. The second form of resistance was shown by a subject's inflexibility of rating connotative meaning for death related ideas. This was measured by the semantic differential and would appear as clusters on the three factors: evaluative, potency, and activity. The clustering would be expressed by lower variance scores.

Death anxiety in this experiment was measured by the Sarnoff Fear of Death Scale (FDS) (Sarnoff and Corwin, 1959), a five item self-report scale. Four predictions were made: 1) it is more difficult to recognize death related words than neutral words, 2) the magnitude of perceptual defense varies directly with anxiety about death, 3) as anxiety about death increases, so does connotative rigidity, and 4) the magnitude of perceptual defense varies directly with connotative rigidity.

Predictions one and four were supported. Death words took significantly more trials to recognize than neutral words $(p<.0 I)$, and differences between mean trials to recognize death and neutral words correlated negatively (the predicted direction) with the variance of two of three factors on the semantic differential, evaluative $(p<.05)$ and activity $(p<.01)$.

The authors suggest that the failure to support 
predictions two and three may be due to the inadequacy of the FDS to tap deeper aspects of affective orientation. They also state that although there seems to be a consistency in cognition of individual's attitudes toward death, the study did not show any relationship between cognitive and affective aspects of attitudes.

Thus, there seems to be some agreement among the studies reported above. Individuals seem to be concerned on a less-than-conscious level with the concept of death, as measured by the GSR, word association tasks, and tachistoscopic recognition tasks. 
THE PROBLEM

Kastenbaum and Costa (1977) assert that there is a need for repliqation of studies of death attitudes and systematic comparison of direct and indirect measures. The present study is essentially a replication of the Golding, et al. (1966) study reported above but with the use of an improved instrument. The Self-Administered Threat Index (SATI) which has shown high reliability and validity, independence from a measure of social desirability, and which is anchored to personal meaning of death, appears to have some advantage over other self-report measures. It will replace the Sarnoff Fear of Death Scale in the previous study. The SATI, as yet, has not been compared to the indirect measures used in the Golding, et al. (1966) study. Another advantage of: the SATI is that it is based on the cognitive structuring of the individual and may tap deeper levels of threat than the Sarnoff Fear of Death Scale, meeting a criticism of the latter by Golding, et ai. (1966). The present study will have similar hypotheses to the previous study in that hypotheses one and four are identical to the Golding, et al. (1966) study and hypotheses two and three replace the SATI for the Sarnoff Fear of Death Scale. The hypotheses for this study are: 
1) The mean number of trials to recognize death words will be significantly greater than the mean number of trials to recognize neutral words.

2) SATI scores will correlate positively with the differences between mean trials to recognize death words and mean trials to recognize neutral words.

3) SATI scores will correlate negatively with the standard deviation scores on the evaluative, potency, and activity factors and the seven individual scales on the Semantic Differential.

4) Differences between mean trials to recognize death and neutral words will correlate negatively with the standard deviation scores on the evaluative, potency and activity factors, and the seven individual scales on the Semantic Differential. 
METHOD

SUBJECTS

Ss were 21 male and 25 female introductory psychology students. The mean age and range of ages for the males were 22.3 and 19 to 30 years old, respectively. For females, the mean age was 22.3 years and the range was 18 to 33 years old. Undergraduates were used because the constructs of the SATI were originally elicited from undergraduates and Krieger, et al. (1977) caution against generalizing from results obtained from other populations using these particular provided constructs. Ss were both male and female to control for sex related variance. Krieger, et al. (1974) found that males scored significantly higher $(p<.10)$ on the Threat Index than females. The Ss were told their help was necessary in the validation of a new personality inventory but were not informed of the experiment's connection to death concern until the end of the testing. Only native speakers of English or those fluent in English were used as S $s$.

\section{STIMULUS WORDS}

The stimulus words from the Golding, et al. (1966) study were used. They selected their words by having 80 
introductory psychology students rate 40 words on a sevenpoint scale ranging from "highly related to death" (1.0) to "highly related to life" (7.0). Mean ratings of less than 2.5 designated death words and those with means between 2.5 and 5.5 were considered neutral words. Four words from each of these groups were used for the tachistoscopic recognition task. The words in both categories were matched for equal length and frequency in written English and were typed in standard pica type, lower case letters on white $4 \times 6$ cards. The four pairs of words were: dead-tree, cemetery-marriage, corpse-growth, and grave-green. Words from the death category which were used on the Semantic Differential were coffin, death, tomb, perish, and funeral.

\section{APPARATUS}

Recognition thresholds for the experimental words were determined by using a Gerbrands Tachistoscope model T2BC and Gerbrands timer model 130A. An exposure at .01 second duration of flash used by Golding, et al. (1966) was found too short for all $\underline{s}$ in a pilot study. Therefore, duration of flash was determined separately for each $\underline{S}$ as indicated by each S's performance on twelve practice words. This resulted in different recognition thresholds for each $\underline{s}$. The practice words were matched with the experimental words for length and frequency in written English. The number of trials to recognize each of the experimental words was 
counted.

In any word recognition task it is important to control for the $\underline{S}$ s readiness to see the word and report it correctly. Although the words used were controlled for length and frequency of occurrence in written English, there was still the possibility that some $\underline{S} s$ would be more ready to see and report the words in the study because of some event in their lives which increased their readiness to respond. In the present study the most obvious hazard was that some Ss might have a set to respond to death-related words because of chronic or recent experiences relating to such words or to the idea of death--for example, the reading of gothic tales, or a death in the family. It was not practical to inquire about such experiences before the word recognition task, since to do so might have altered the set

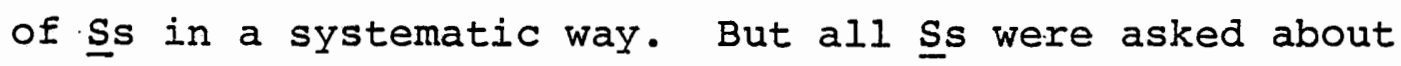
death-related experiences during the debriefing following the data collection.

The Self-Administered Threat Index (SATI) as described by Rainey and Epting (1977) was used to measure death threat. The SATI consists of three separate sheets of paper each with 40 bi-polar constructs. All three sheets are identical except for instructions. The first sheet instructs the $\underline{\mathbf{S}}$ to circle the side with which he would "prefer" to see himself more closely associated. On the second sheet the $\underline{s}$ is to circle the side he more closely associates. with himself, 
and on the third sheet to circle the side he associates to his own death. Scoring consists of counting the number of constructs in which both "preferred self" (P) and "self" (S) are on the same side and "death" (D) is on the opposite side of the same construct. The Semantic Differential was used to rate five death words. Each word was rated by each $\underline{\text { S }}$ on seven scales and analyzed in terms of the three factors evaluation, potency, and activity. The scales for evaluation are: good-bad, valuable-worthless, and fresh-stale; for potency: strong-weak, and large-small; and for activity: active-passive and hot-cold. The standard deviations for the factors evaluation, potency, and activity and for each of the seven separate scales composing these three factors were calculated.

At the end of testing a brief structured interview was administered to each $\underline{s}$. The questions were: 1) Have you had any important personal losses in the recent past? If so, how long ago? 2) Have you or anyone close to you had a serious illness? If so, how long ago? 3) Has anyone close to you died? If so, how long ago? 4) When do you think you will die? 5) Are you afraid of your own death? 6) Do you believe in an after-Iife? 7) Do you have any idea of what this experiment is about? 8) How do you feel about having participated in this experiment? 9) Have you recently read any death related literature, death and dying, novels, or horror stories? 
Copies of all instruments used in the present study, including the SATI, Semantic Differential, the Structured Interview and the Informed Consent form required of each $\underline{s}$, may be found in the Appendix.

\section{PROCEDURE}

Ss were run individually, performing the tachistoscopic recognition task first in a well lighted room. Each $\underline{S}$ was instructed to focus on a point centered between two horizontal lines on the white field. The lines were drawn lightly with pencil, two inches long and one inch apart. Next, each $\underline{S}$ was told that the task was to verbalize the word he saw.flashed and to verbalize any guesses he might have. There was a three second interval between flashes of the same stimulus word. The number of trials to correctly verbalize each word were recorded.

Recognition using .01 second duration of flash used by Golding, et al. (1966) was found too short for all Ss in a pilot study. Therefore, duration of flash was determined separately for each $\underline{S}$ by the procedure below.

Twelve practice words which were in random order for each $\underline{S}$ were presented first to rule out any practice effect that might have occurred during the presentation of the experimental words and to determine the duration of flash at which each $\underline{\mathbf{s}}$ could correctly report the neutral stimulus words. This was done by beginning the practice trials with 
a .03 second duration of flash for the first practice word (three one-hundredths of a second was the mean exposure for pilot study $\underline{S}$ ). If an $\underline{S}$ correctly identified the stimulus word in 20 flashes or less, the duration was decreased by .005 second for the second practice word. This was continued until the s could no longer correctly identify the word. At this point, the duration was increased by .001 second for each successive word until the $\underline{S}$ could correctly identify the stimulus. This became the experimental duration of flash for that $\underline{S}$ and was held constant for all eight experimental words. For those $\underline{S}$ s who did not correctly verbalize the first practice word at .03 second in 20 flashes or less, the procedure was reversed by lengthening the duration by .005 second for the next word stimulus. This was continued for each successive word until the $\underline{S}$ could correctly identify the word in 20 flashes or less. When the word was correctly identified, the duration was shortened by .001 second for the next practice word. This was continued until the $\underline{s}$ could no longer recognize the stimulus word being presented. The duration preceding this last one became the experimental duration of flash for that S. The experimental words were presented immediately following the practice words. The total number of trials to recognize the experimental words was recorded. Following the tachistoscopic recognition task, each S was taken into a different room and administered the SATI 
and Semantic Differential in that order. The $\underline{S}$ was told that there were five pages and instructions were self explanatory, to do the test in order, not to look forward, and not to look back.

After the completion of all tasks, each $\underline{S}$ was administered the brief structured interview. This asked for additional information about recent life-death issues that might have influenced their responses. This was also the time to debrief the $\underline{S}$ and to note any adverse reactions the S may have experienced.

\section{ANALYSIS}

A t-test for matched pairs was used to determine the difference between mean trials to recognize death and neutral words. The standard deviation was used as the measure of variance for the Semantic Differential rather than the variance score used in the Golding, et al. (1966) study because the standard deviation minimizes the effect of lone extreme scores. Pearson's $\underline{r}$ was used to correlate the SATI and differences between mean trials to recognize death and neutral words, the SATI and standard deviations of the Semantic Differential, and the differences between mean trials to recognize death and neutral words and standard deviations of the Semantic Differential. A t-test for independence was used to test sex differences on the SATI. The present study is a partial replication of the 
Golding, et al. (1966) study with the SATI replacing the Sarnoff Fear of Death Scale and with an additional structured interview to note recent life-death experiences that may have influenced the $\underline{S}$ 's responses, to determine any adverse reactions that the $\underline{S}$ may have experienced, and to serve as a de-briefing time. The tachistoscopic recognition task was changed to include twelve practice words and to allow for varying recognition thresholds for neutral words among $\underline{S}$. The subject group differed from the Golding, et al. (1966) study; in the present study it was larger and contained both males and females. Analysis differed in that (a) standard deviations of scores on the semantic Differential were used instead of variance scores and (b) individual scales and factors on the Semantic Differential were included in the correlational analysis, whereas the Golding, et al. (1966) study only included the three factors. 


\section{RESULTS}

The t-test for independence of the sets of SATI scores for men and for women was not significant at $p<.10$ $(t=.9419, \mathrm{df}=44)$, which does not support the finding of Krieger, et al. (1974) that females scored lower than males on the Threat Index. The mean for males was 10.62 and for females 13.60 on the SATI. The overall mean was 12.24 .

A summary of the data collected in the experiment appears in the Appendix.

The results of the $t$-test for matched pairs testing the difference between mean trials to recognize death words and neutral words was significant at $p<.0005$ ( $t=5.1340$, $\mathrm{df}=45)$. Thus, the first hypothesis, that death words take more trials to recognize than neutral words is supported. Relevant to this hypothesis are the means of 7.20 trials to recognize death words and 4.53 trials to recognize neutral words. The mean trials for the individual words are presented in TABLE I. Of the 46 Ss, 34 (74\%) showed differences in the predicted direction, one (2\%) had a difference of zero, and 11 (24\%) had differences in the opposite direction predicted.

The correlation between mean differences to recognize death and neutral words and scores on the SATI was not 
TABIE I

MEAN TRIALS TO RECOGNIZE NEUTRAL WORDS AND DEATH WORDS NEUTRAL WORDS DEATH WORDS

\begin{tabular}{lllr}
\hline tree & 3.78 & dead & 9.24 \\
green & 5.26 & grave & 3.56 \\
growth & 2.98 & corpse & 17.50 \\
marriage & 6.09 & cemetery & 8.48 \\
\hline total mean & 4.53 & & 7.20
\end{tabular}

significant at the .05 level $(r=.1696, p<.13)$. Thus, the second hypothesis that perceptual defense is positively correlated to degree of death threat is not supported.

The correlations relevant to the third and fourth hypotheses are presented in TABLE II: 


\section{TABLE II}

PEARSON'S. $Y$ COEFFICIENTS FOR THE STANDARD DEVIATIONS OF THE FACTŌRS AND SCALES OF THE SEMANTIC DIFFERENTIAL WITH SCORES ON THE SATI AND WITH THE MEAN

DIFFERENCE OF TRIALS TO REPORT NEUTRAI AND DEATH-RELATED WORDS 1

\begin{tabular}{llc} 
& & MEAN DIFFERENCE \\
SEMANTIC DIFFERENTIAL & SATI & OF TRIALS \\
\hline Evaluative dimension & $-.4863 \mathrm{~d}$ & .0507 \\
good-bad & $-.3953 \mathrm{c}$ & -.0098 \\
valuable-worthless & $-.3684 \mathrm{~b}$ & .0455 \\
fresh-stale & $-.3504 \mathrm{~b}$ & .1366 \\
Potency Dimension & -.1344 & -.1116 \\
strong-weak & $-.2808 \mathrm{a}$ & .0607 \\
large-small & -.0431 & -.2344 \\
Activity Dimension & -.2285 & .0170 \\
active-passive & $-.5551 \mathrm{e}$ & .0895 \\
hot-cold & -.2210 & -.0279 \\
\hline a $p<.05$ & 1 N $=46$ for all entries \\
b p $<.01$ & in the table. See text \\
c p $<.005$ & for explanation. \\
d p $<.001$ & & \\
e p $<.0001$ &
\end{tabular}

Correlations between the standard deviations of the Semantic Differential and the SATI were all in the predicted direction. Only one of the factors, Evaluative, correlated significantly $(p<.001)$ with the SATI. Five of the seven scales also correlated significantly, the three scales of the evaluative factor and one scale each for the potency and activity factors. Therefore, the third hypothesis that SATI scores on the evaluative, potency, and activity factors and the individual scales on the semantic Differential is 
supported.

None of the correlations between the standard deviations of the Semantic Differential and the mean differences to recognize death and neutral words were significant. All of the correlations fluctuate around zero. Therefore, the fourth hypothesis that differences between mean trials to recognize death and neutral words will|correlate negatively with the standard deviation scores lon the evaluative, potency, and activity factors and seven individual scales on the Semantic Differential is not supported. 


\section{DISCUSSION}

The results indicate that death words (requiring a mean of 7.20 trials) are more difficult to recognize than neutral words (requiring a mean of 4.53 trials). This replicates the findings of Golding, et al. (1966) who report a mean of 6.52 trials to report death words and a mean of 4.53 trials to report neutral words. Golding, et al. (1966) suggest that the difference in recognizing death and neutral words is a function of stimulus emotionality. This interpretation is supported by the studies of Alexander, et al. (1957) and Alexander and Adlerstein (1958) who found significantly lowered skin resistance on the GSR to deathrelated words compared to neutral words. It would seem, therefore, that death words elicit an emotional response in the $\underline{S}$ which is demonstrated by an increase in the number of trials required to recognize and report the death word.

The third hypothesis that SATI scores would correlate negatively with standard deviation scores on the Semantic Differential was supported. The SATI did|significantly correlate with the standard deviations of one factor (Evaluative) and five of seven scales of the Semantic Differential. Golding, et al. (1966) defined connotative rigidity as "a form of resistance on the part of 
consciousness against ideas of death." This formulation of connotative rigidity seems to be related to Personal Construct Theory upon which the SATI is based. Krieger, et al. (1974) state that "...death would be threatening to a person in proportion to the amount of systematic reorganization necessary to construe death as a personal reality." It appears from the results that a person's reluctance to change his construct system in order to anticipate death is related to his resistance against ideas of death which appears as clustering (little variance among his ratings) on the Semantic Differential.

The picture becomes more complicated when looking at the tests of hypotheses two and four. Neither the SATI nor the standard deviations of the Semantic Differential correlated significantly with the difference between mean recognition trials of death and neutral words. The correlation between the SATI and mean differences was in the predicted direction although not significant. The ten correlations between the standard deviations and mean differences all fluctuated around zero. These results would suggest that death threat as measured by the SATI and connotative rigidity as measured by the Semantic Differential are not related to perceptual defense. While death words do seem to elicit an emotional response in an S, the magnitude of this response does not seem to be related to the magnitude of death threat or to connotative 
rigidity. It is possible that the tachistoscopic recognition task is measuring a different level of death attitude than the SATI and Semantic Differential. This is supported by Feifel and Branscomb's (1973) findings that of 371 Ss only 19 were consistently "fearful" of death at three different levels of measurement and only six were consistently "not afraid" at all three levels.

Evidence against the above interpretation is the Golding, et al. (1966) study, where a significant relationship was found between mean difference to recognize death and neutral words and the pattern of response on the Semantic Differential (hypothesis four in the present study). They found that connotative rigidity and perceptual defense were significantly related with correlations of -.32 $(p<.05)$ for the evaluative factor and $-.44(p<.01)$ for the activity factor. If connotative rigidity was related to perceptual defense in their study perhaps death threat as measured by the SATI would also be related to perceptual defense. The lack of replication of this finding (hypothesis four) is difficult to explain, considering that hypothesis one, "death words take Ionger to recognize", was supported. What was not replicated was that the magnitude of the difference between the means was not related to clustering on the Semantic Differential.

Procedural differences between the two studies may have been responsible for the lack of replication. A 
larger $N$ of 46 , including males and females, was used in the present study; 30 males only were used in the Golding, et al. (1966) study. 2) Golding, et al. (1966) report presenting the eight experimental words at .01 second duration of flash. The procedure of the present study included twelve practice words and determined individual durations for each $\underline{S}$. 3) The exact nature of the presentation stimulus words in the Golding, et al. (1966) study is unknown and might have been sufficiently different to affect results. 4) In the present study the standard deviation scores were used instead of variance scores on the Semantic Differential when making comparisons with that instrument. As a check on the failure to replicate the findings of Golding, et al. correlation coefficients were recomputed between the semantic differential and the other two variables in the study using variance scores on the Semantic Differential (as done in the present study). The results appear in Table III. Again there was a failure to replicate the results of Golding, et al. for hypothesis four, even when using exactly the same kind of analysis done in that study

Further investigation is needed into the contradictory results of the two studies. A more intensive training period is suggested for the tachistoscopic recognition task. This should include more practice words incorporated into a signal detection design which would 


\section{TABLE III}

PEARSON'S I COEFFICIENTS FOR THE VARIANCE SCORES OF THE FACTORS AND SCALES OF THE SEMANTIC DIFFERENTIAL WITH SCORES ON THE SATI AND WITH THE MEAN DIFFERENCE OF TRIALS TO REPORT NEUTRAL AND DEATH-RELATED WORDS. 1

\begin{tabular}{llc} 
SEMANTIC DIFFERENTIAL & SATI & $\begin{array}{c}\text { MEAN DIFFERENCE } \\
\text { OF TRIALS }\end{array}$ \\
\hline Evaluative Dimension & $-.4416 \mathrm{c}$ & .0732 \\
good-bad & $-.4032 \mathrm{c}$ & -.0317 \\
valuable-worthless & $-.3758 \mathrm{~b}$ & .0124 \\
fresh-stale & $-.3146 \mathrm{a}$ & .1473 \\
Potency Dimension & -.1387 & -.1504 \\
strong-weak & $-.2909 \mathrm{a}$ & .0782 \\
large-small & .0091 & -.2344 \\
Activity Dimension & -.1263 & -.0256 \\
active-passive & $-.3416 \mathrm{a}$ & .0477 \\
hot-cold & -.0572 & -.1009 \\
\hline a $<.05$ & $1 \mathrm{~N}=46$ for all entries \\
b p $<.01$ & in the table. See text \\
c p $<.005$ &
\end{tabular}

would allow better control for an individual's different readiness to report words. Some $\underline{S}$ s reported that they would see the death words but would wait a flash or two before reporting it. Some said they thought the experimenter would think they were morbid if they incorrectly guessed a death word. It is also important to find what relationships exist between the SATI and other personality correlates such as external-internal locus of control (Dickstein and Blatt, 1966). It also seems important for future experiments to 
report more explicitly the nature of the stimulus words and the tachistoscopic procedures.

The SATI may have some clinical applications in the future. Those who work with dying patients may be assessed with the SATI to determine if they need additional training or counseling about their own thoughts and feelings of death. This may be done with survivors who are in the grieving process and with dying patients themselves. Other clinical work may be done with suicidal patients (Lester, 1967b) and the SATI. The SATI may also prove beneficial in working with elderly persons and their adjustment to later life.

The present study attempted to relate two forms of cognitive resistance as reported by Golding, et al. (1966) with the SATI introduced by Rainy and Epting (1977). It was found that ss took more trials to recognize and report death words than neutral words. The SATI was found related to connotative rigidity as measured by the Semantic Differential and not found related to perceptual defense as measured by a tachistoscopic recognition task. Contrary to Golding, et al. (1966) study, the present study found no relation between perceptual defense and connotative rigidity. 


\section{SELECTED BIBLIOGRAPHY}

Alexander, I.E., Colley, R.S., and Adlerstein, A.M. Is death a matter of indifference? The Journal of Psychology, 1957, 43, 277-283.

Alexander, I.E., and Adlerstein, A.M. Affective responses to the concept of death in a population of children and early adolescents. The Journal of Genetic Psychology, 1958, 93, 16 7-177.

Christ, A.E. Attitudes toward death among a group of acute geriatric psychiatric patients. Journal of Gerontology, 1961, 16, 56-59.

Crowne, D.P. and Marlowe, D. A new scale of social desirability independent of psychopathology. Journal of Consulting Psychology, 1960, 24(4), 349-354.

Dickstein, I.S., and Blatt, s. Death concern, futurity, and anticipation. Journal of Consulting Psychology, $1966,31,11-17$.

Durkheim, E. Suicide, 1951. Glencoe, Illinois: Free Press.

Durlak, J.A. Relationship between various measures of death concern and fear of death. Journal of Consulting and Clinical Psychology, 1973, 4 1 (1), 162.

Farberow, N.I., and Schneidman, E.S., eds. The Cry for Help, 1965. New York: McGraw-Hill.

Fechner, G.T. The Iittle Book of Life After Death, 1904. Boston: Little, Brown.

Feifel, H. The Meaning of Death, 1959. New York: McGrawHill.

Feifel, H. Symposium: Death attitudes. Journal of Gerontology, 1961, 16, 61-63.

Feifel, H., and Branscomb, A:B. Who's afraid of death? Journal of Abnormal Psychology, 1973, 81 (3), 282-288.

Golding, S.L., Atwood, G.E., and Goodman, R. A. Anxiety and two cognitive forms of resistance to the idea of death. Psychological Reports, 1966, 18, 359-364.

Hall, G.S. Thanatophobia and immortality. Americal Journal of Psychology, 1915, 26, 550-613.

James, W. The Varieties of Religious Experience, 1910. Boston: Longmans, Green.

Kastenbaum, R., and Aisenberg, R. The Psychology of Death, 1972. New York: Springer:

Kastenbaum, R., and Costa, P.T. Psychological Perspectives on Death. Annual Review of Psychology, 1977, 28,

225-249. 
Klug, I., and Boss, M. Factorial structure of the death concern scale. Psychological Reports, 1976, 38, 107-112.

Krieger, S.R., Epting, F.R., and Leitner, L.M. Personal constructs, threat, and attitudes toward death. Omega, 1974, $5,299-310$.

Krieger, S.R., Epting, F.R., and Hays C.H. Assessing the threat of death. Unpublished manuscript, 1977.

Kubler-Ross, E. On Death and Dying, 1969. New York: MacMillan.

Lester, D. A scale measuring the fear of death; its construction and consistency. 1966. ADI Auxiliary Publications Project, Photoduplication Service, Library of Congress, Washington, D.C. 29540. Document No. 9449 .

Lester, D. Experimental and correlational studies of the fear of death. Psychological Bulletin, 1967, 67(1), 27-36. (a)

Iester, D. Fear of death of suicidal persons. Psychological Reports, 1967, 20, 1077-1078.

(b)

Meissner, W.W. Affective response to psychoanalytic death symbols. Journal of Abnormal and Social Psychology, $1958,56,295-299$.

Munnichs, J.M.A. Symposium: Death Attitudes. Journal of Gerontology, 1961, 16, 60-61.

Rainey, I.C., and Epting, F.R. Death threat constructions in the student and the prudent. Omega, 1977, $\underline{8}(1)$, 19-28.

Sarnoff, I., and Corwin, S.M. Castration anxiety and the fear of death. Journal of Personality, 1959, 27, 374-385.

Templer, D.I. The construction and validation of a death anxiety scale. The Journal of General Psychology, $1970,82,165-177$. 


\section{APPENDIX}

ITEM

PAGE

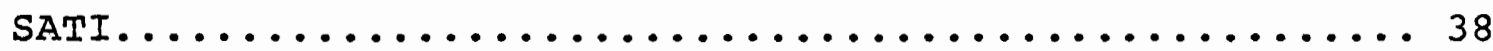

Semantic DifferentiaI.........................41

Structured Interview..........................43

Informed Consent Form..........................44

Summary of Data by subject....................... 45 
For each dimension below circle the side with which you would prefer to see yourself more closely associated. For example, would you prefer to see yourself associated more with the term "predictable" or "random"?

\begin{tabular}{|c|c|c|c|}
\hline predictable & - random & productive & - unproductive \\
\hline empty & - meaningful & learning & - not learning \\
\hline sad & - happy & purposeful & - not purposeful \\
\hline personal & - impersonal & responsible & - not responsible \\
\hline $\begin{array}{l}\text { lack of } \\
\text { control }\end{array}$ & - control & bad & - good \\
\hline satisfied & - dissatisfied & not caring & - caring \\
\hline $\begin{array}{l}\text { relating to } \\
\text { others }\end{array}$ & $\begin{array}{l}\text { not relating } \\
\text { to others }\end{array}$ & crazy & $\begin{array}{l}\text { - healthy } \\
\text { personality }\end{array}$ \\
\hline pleasure & - pain & conforming & - not conforming \\
\hline feels bad & - feels good & animate & - inanimate \\
\hline objective & - subjective & weak & - strong \\
\hline alive & - dead & useful & - useless \\
\hline $\begin{array}{l}\text { helping } \\
\text { others }\end{array}$ & $\begin{array}{l}\text { - being } \\
\text { selfish }\end{array}$ & closed & - open \\
\hline specific & - general & peaceful & - violent \\
\hline kind & - cruel & freedom & - restriction \\
\hline incompetent & - competent & non-existence & - existence \\
\hline insecure & - secure & understanding & - not understanding \\
\hline static & - changing & sick & - healthy \\
\hline unnaturaI & - natural & stagnation & - growth \\
\hline $\operatorname{calm}$ & - anxious & abstract & - concrete \\
\hline easy & - hard & hope & - no hope \\
\hline
\end{tabular}


Below is a list of bipolar dimensions. For each dimension please circle the side with which you see yourself more closely associated. For example, do you associate yourself more with the term "predictable" or "random"?

\begin{tabular}{|c|c|c|c|}
\hline predictable & - random & productive & - unproductive \\
\hline empty & - meaningful & learning & - not learning \\
\hline sad & - happy & purposeful & - not purposeful \\
\hline personal & - impersonal & responsible & - not responsible \\
\hline $\begin{array}{l}\text { lack of } \\
\text { control }\end{array}$ & - control & bad & - good \\
\hline satisfied & - dissatisfied & not caring & - caring \\
\hline $\begin{array}{l}\text { relating to } \\
\text { others }\end{array}$ & $\begin{array}{l}\text { - not relating } \\
\text { to others }\end{array}$ & crazy & $\begin{array}{l}\text { - healthy } \\
\text { personality }\end{array}$ \\
\hline pleasure & - pain & conforming & - not conforming \\
\hline feels bad & - feels good & animate & - inanimate \\
\hline objective & - subjective & weak & - strong \\
\hline alive & - dead & useful & - useless \\
\hline $\begin{array}{l}\text { helping } \\
\text { others }\end{array}$ & $\begin{array}{l}\text { - being } \\
\text { selfish }\end{array}$ & closed & - open \\
\hline specific & - general & peaceful & - violent \\
\hline kind & - cruel & freedom & - restriction \\
\hline incompetent & - competent & non-existence & - existence \\
\hline insecure & - secure & understanding & - not understanding \\
\hline static & - changing & sick & - healthy \\
\hline unnatural & - natural & stagnation & - growth \\
\hline $\operatorname{calm}$ & - anxious & abstract & - concrete \\
\hline easy & - hard & hope & - no hope \\
\hline
\end{tabular}


For each dimension circle the side with which you most closely associate your own death.

\begin{tabular}{|c|c|c|c|}
\hline predictable & - random & productive & - unproductive \\
\hline empty & - meaningful & learning & - not learning \\
\hline sad & - happy & purposeful & - not purposeful \\
\hline $\begin{array}{l}\text { lack of } \\
\text { control }\end{array}$ & - control & bad & - good \\
\hline satisfied & - dissatisfied & not caring & - caring \\
\hline $\begin{array}{l}\text { relating to } \\
\text { others }\end{array}$ & $\begin{array}{l}\text { - not relating } \\
\text { to others }\end{array}$ & crazy & $\begin{array}{l}\text { - healthy } \\
\text { personality }\end{array}$ \\
\hline pleasure & - pain & conforming & - not conforming \\
\hline feels bad & - feels good & animate & - inanimate \\
\hline objective & - subjective & weak & - strong \\
\hline alive & - dead & useful & - useless \\
\hline $\begin{array}{l}\text { helping } \\
\text { others. }\end{array}$ & $\begin{array}{l}\text { - being } \\
\text { selfish }\end{array}$ & closed & - open \\
\hline specific & - general & peaceful & - violent \\
\hline kind & - cruel & freedom & - restriction \\
\hline incompetent & - competent & non-existence & - existence \\
\hline insecure & - secure & understanding & - not understanding \\
\hline static & - changing & sick & - healthy \\
\hline unnatual & - natural & stagnation & - growth \\
\hline calm & - anxious & abstract & - concrete \\
\hline easy & - hard & hope & - no hope \\
\hline
\end{tabular}


On this page there are words in capitalized letters at the top of each section. You will notice that there are seven pairs of opposites underneath each capitalized word. Between each of the pairs of opposites there are seven lines. You are to place a check mark on one of the seven lines that are between the two opposite words and the check mark should indicate what the word at the top of the section means to you.

Good

Valuable

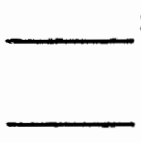

: : : : Bad

Strong

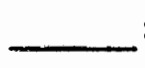
: : : : Worthless

Iarge : : Weak

Hot

Active

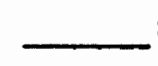
: :

-
: : : Small

Fresh

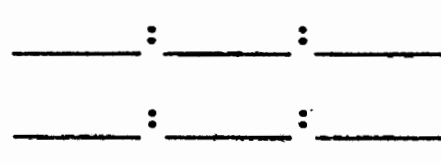
: : Cold : $:$ : Passive

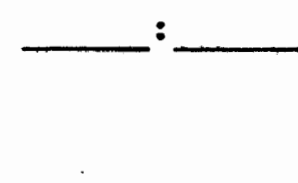
: : : Stale

\section{DEATH}

Good
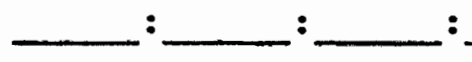
: : Bad

Valuable
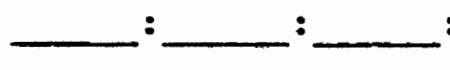
: Worthless

Strong

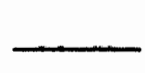
$:$ : : Weak

Large

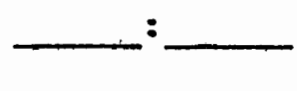
$:$ : Small

Hot

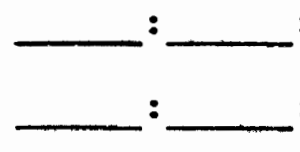
: : Cold

Active : : Passive

Fresh

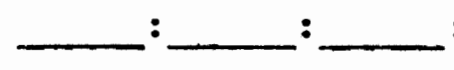
: : Stale 


\section{TOMB}

Good

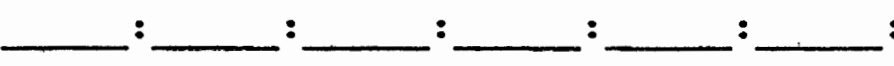

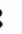

Bad

Valuable

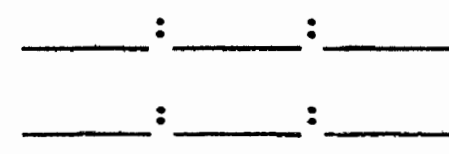

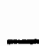

Worthless

Strong : : Weak

Large

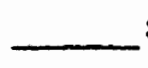
:

Small

Hot

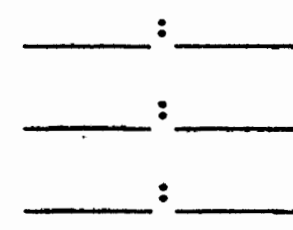

:

Cold

Active

Fresh

:

Passive

Stale

\section{PERISH}

Good

Valuable

Strong

Large

Hot

Active

Fresh

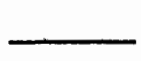

: : : : : : Bad

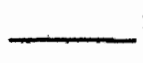
: : : Worthless<smiles>C=C</smiles>
: : : Weak Small

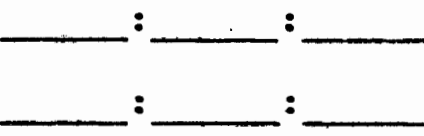
: : : : Cold

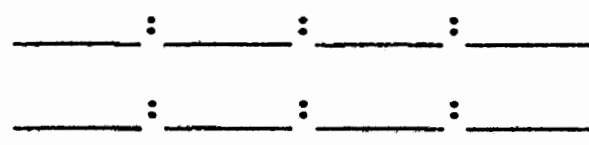
: Passive Stale

\section{FUNERAL}

Good

Valuable

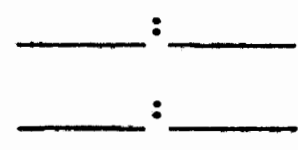
: : : Bad strong

Large

Hot

Active

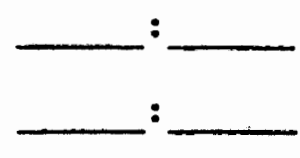

Worthless Weak Sma1I

Cold Passive

Fresh

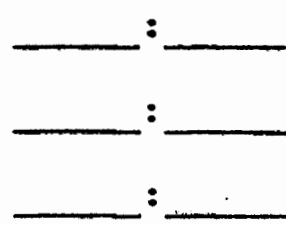




\section{STRUCTURED INTERVIEW}

Age :

Sex :

Have you had any important personal losses in the recent past? If so, how long ago?

Have you or anyone close to you had a serious illness? If so, how long ago?

Has anyone close to you died? If so, how long ago?

When do you think you will die?

Are you afraid of your death?

Do you believe in an afterlife?

Do you have any idea of what this experiment is about?

How do you feel about having participated in this experiment?

(Debrief) Briefly describe that the experiment is about death and the threat of death. Ask subject not to share his/her experience with the experiment until the experimenter returns to the class to explain the findings.

Have you recently read any death-related literature, death and dying, novels, or horror stories, (or anything subject thinks is related). 


\section{INFORMED CONSENT}

I, hereby agree to serve as a subject in the research project on the Personality Index conducted by Henry Miller.

I understand that the study involves taking three brief tests and a short interview.

I understand that possible risks to me associated with this study are some possible psychological discomfort and one hour of my time.

It has been explained to me that the purpose of the study is to learn about personality correlates to a new personality index.

I may not receive any direct benefit from participating in this study, but my participation may help to increase knowledge which may benefit others in the future.

Henry Miller has offered to answer any questions I may have about the study and what is expected (required) of me in the study.

I understand that my participation is voluntary, that I am free to withdraw from participation in this study at any time without jeopardizing my relationship with Portland state University and that my grade in the class will not be affected in any way.

I have read and understand the foregoing information.

Date Signature

If you experience problems that are the result of your participation in this study, please contact Richard Streeter, Office of Graduate Studies and Research, 10.5 Neuberger Hall, Portland State University, 229-3423. 
DATA FOR FEMALES

DEATH WORDS

NEUTRAI WORDS

\begin{tabular}{|c|c|c|c|c|c|c|c|c|c|c|c|c|}
\hline $\begin{array}{l}\text { 怘 } \\
\text { 旨 } \\
\text { 岕 } \\
\text { 号 }\end{array}$ & 辰 & $\begin{array}{l}\text { 国 } \\
\text { 虫 }\end{array}$ & $\begin{array}{l}\text { ry } \\
02 \\
01 \\
01 \\
0 \\
0\end{array}$ & 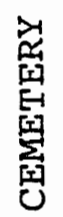 & 昵 & $\begin{array}{l}\text { 留 } \\
\text { 出 }\end{array}$ & 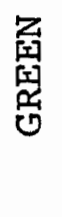 & 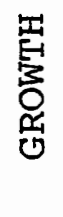 & 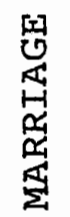 & $\begin{array}{l}\text { 봅 } \\
\text { 엉 }\end{array}$ & 崫 & 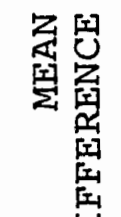 \\
\hline
\end{tabular}

\begin{tabular}{llllllllllllll}
\hline 33 & .024 & 1 & 7 & 46 & 4 & 58 & 11 & 3 & 1 & 4 & 19 & 19 & 9.75
\end{tabular} $\begin{array}{llllllllllllll}24 & .025 & 3 & 4 & 7 & 11 & 25 & 1 & 2 & 3 & 2 & 8 & 24 & 4.25\end{array}$ $\begin{array}{llllllllllllll}18 & .067 & 8 & 1 & 4 & 3 & 16 & 1 & 2 & 4 & 1 & 8 & 9 & 2.00\end{array}$ $\begin{array}{llllllllllllll}20 & .062 & 2 & 1 & 14 & 7 & 24 & 2 & 12 & 4 & 32 & 50 & 29 & -6.50\end{array}$ $\begin{array}{llllllllllllll}1.9 & .024 & 9 & 1 & 2 & 5 & 17 & 5 & 8 & 1 & 3 & 17 & 31 & 0\end{array}$ $\begin{array}{llllllllllllll}25 & .021 & 1 & 1 & 41 & 4 & 47 & 1 & 1 & 1 & 2 & 5 & 10 & 10.50\end{array}$ $\begin{array}{llllllllllllll}18 & .035 & 4 & 2 & 53 & 5 & 64 & 3 & 4 & 3 & 6 & 16 & 30 & 12.00\end{array}$ $\begin{array}{llllllllllllll}31 & .023 & 1 & 23 & 37 & 25 & 86 & 7 & 21 & 2 & 1 & 31 & 4 & 13.75\end{array}$ $\begin{array}{llllllllllllll}18 & .020 & 3 & 3 & 57 & 4 & 67 & 7 & 3 & 2 & 3 & 15 & 3 & 13.00\end{array}$ $\begin{array}{llllllllllllll}25 & .020 & 12 & 1 & 10 & 2 & 25 & 1 & 1 & 5 & 2 & 8 & 10 & 4.25\end{array}$ $\begin{array}{llllllllllllll}21 & .035 & 14 & 3 & 3 & 33 & 53 & 6 & 2 & 3 & 4 & 15 & 11 & 9.50\end{array}$ $\begin{array}{llllllllllllll}22 & .015 & 12 & 3 & 5 & 5 & 25 & 3 & 6 & 4 & 3 & 16 & 13 & 2.25\end{array}$ $\begin{array}{llllllllllllll}19 & .025 & 1 & 2 & 24 & 4 & 31 & 2 & 1 & 1 & 1 & 5 & 17 & 6.25\end{array}$ $\begin{array}{llllllllllllll}31 & .020 & 1 & 1 & 1 & 3 & 6 & 3 & 1 & 1 & 2 & 7 & 16 & -.25\end{array}$ $\begin{array}{llllllllllllll}19 & .015 & 8 & 5 & 24 & 7 & 44 & 3 & 7 & 1 & 4 & 15 & 20 & 7.25\end{array}$ $\begin{array}{llllllllllllll}18 & .020 & 28 & 1 & 34 & 30 & 93 & 9 & 13 & 1 & 2 & 25 & 30 & 17.00\end{array}$ $\begin{array}{llllllllllllll}26 & .026 & 1 & 1 & 26 & 1 & 29 & 1 & 2 & 3 & 4 & 10 & 15 & 4.75\end{array}$ $\begin{array}{llllllllllllll}18 & .016 & 36 & 7 & 32 & 20 & 95 & 8 & 23 & 14 & 14 & 59 & 6 & 9.00\end{array}$ $\begin{array}{llllllllllllll}21 & .026 & 2 & 1 & 1 & 1 & 5 & 5 & 1 & 2 & 10 & 18 & 3 & -3.25\end{array}$ $\begin{array}{llllllllllllll}21 & .030 & 5 & 2 & 13 & 32 & 52 & 3 & 14 & 1 & 24 & 42 & 3 & 2.50\end{array}$ $\begin{array}{llllllllllllll}19 & .035 & 4 & 2 & 10 & 8 & 24 & 1 & 1 & 3 & 1 & 6 & 0 & 4.50\end{array}$ $\begin{array}{llllllllllllll}25 & .017 & 1 & 1 & 21 & 14 & 37 & 3 & 1 & 1 & 1 & 6 & 4 & 7.75\end{array}$ $\begin{array}{llllllllllllll}20 & .085 & 3 & 3 & 4 & 2 & 12 & 2 & 2 & 1 & 2 & 7 & 9 & 1.25\end{array}$ $\begin{array}{llllllllllllll}26 & .017 & 2 & 2 & 4 & 3 & 11 & 1 & 3 & 2 & 9 & 15 & 11 & -1.00\end{array}$ $\begin{array}{llllllllllllll}20 & .025 & 10 & 2 & 31 & 1 & 44 & 13 & 4 & 10 & 1 & 28 & 13 & 4.00\end{array}$ 
DATA FOR MALES

DEATH WORDS

四 总
NEUTRAL WORDS

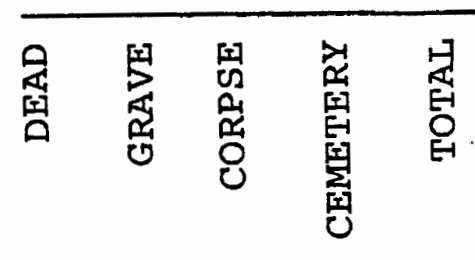

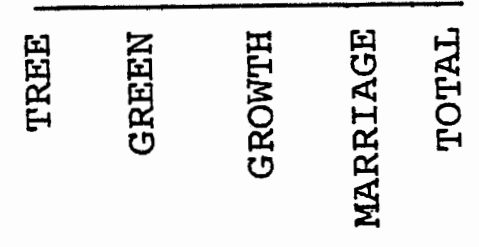

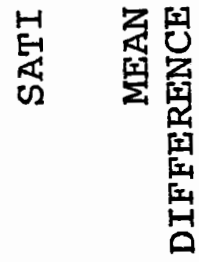

$\begin{array}{llllllllllllll}26 & .030 & 4 & 4 & 3 & 4 & 15 & 2 & 2 & 6 & 3 & 13 & 9 & .50\end{array}$ $\begin{array}{llllllllllllll}25 & .020 & 6 & 2 & 9 & 7 & 24 & 1 & 2 & 12 & 16 & 31 & 9 & -1.75\end{array}$ $\begin{array}{llllllllllllll}19 & .025 & 1 & 1 & 3 & 5 & 10 & 1 & 1 & 1 & 4 & 7 & 15 & .75\end{array}$ $\begin{array}{llllllllllllll}23 & .020 & 7 & 2 & 4 & 4 & 17 & 13 & 7 & 4 & 5 & 29 & 0 & -3.00\end{array}$ $\begin{array}{llllllllllllll}24 & .022 & 29 & 2 & 24 & 2 & 57 & 12 & 11 & 2 & 10 & 35 & 4 & 5.50\end{array}$ $\begin{array}{llllllllllllll}23 & .050 & 5 & 4 & 32 & 4 & 45 & 2 & 6 & 1 & 4 & 13 & 22 & 8.00\end{array}$ $\begin{array}{llllllllllllll}19 & .026 & 1 & 9 & 9 & 14 & 33 & 5 & 2 & 5 & 24 & 36 & 23 & -.75\end{array}$ $\begin{array}{llllllllllllll}20 & .020 & 22 & 5 & 13 & 4 & 44 & 2 & 2 & 1 & 3 & 8 & 38 & 9.00 .\end{array}$ $\begin{array}{llllllllllllll}20 & .015 & 3 & 2 & 9 & 8 & 22 & 9 & 3 & 4 & 8 & 24 & 1 & -.50\end{array}$ $\begin{array}{llllllllllllll}27 & .029 & 52 & 7 & 41 & 3 & 103 & 4 & 4 & 3 & 1 & 12 & 10 & 22.75\end{array}$ $\begin{array}{llllllllllllll}21 & .026 & 5 & 4 & 9 & 1 & 19 & 5 & 2 & 2 & 2 & 11 & 12 & 2.00\end{array}$ $\begin{array}{llllllllllllll}19 & .085 & 30 & 5 & 14 & 16 & 65 & 2 & 11 & 4 & 3 & 20 & 2 & 11.25\end{array}$ $\begin{array}{llllllllllllll}24 & .021 & 2 & 6 & 5 & 4 & 17 & 2 & 4 & 1 & 4 & 11 & 10 & 1.50\end{array}$ $\begin{array}{llllllllllllll}21 & .065 & 38 & 2 & 58 & 55 & 153 & 1 & 24 & 5 & 12 & 42 & 25 & 27.75\end{array}$ $\begin{array}{llllllllllllll}20 & .018 & 8 & 1 & 2 & 6 & 17 & 3 & 4 & 2 & 1 & 10 & 11 & 1.75\end{array}$ $\begin{array}{rrrrrrrrrrrrrr}21 & .029 & 4 & 2 & 2 & 1 & 9 & 3 & 1 & 2 & 5 & 11 & 8 & -.50\end{array}$ $\begin{array}{llllllllllllll}19 & .019 & 9 & 2 & 1 & 9 & 21 & 1 & 2 & 1 & 21 & 25 & 7 & -1.00\end{array}$ $\begin{array}{llllllllllllll}30 & .030 & 3 & 2 & 6 & 3 & 14 & 1 & 2 & 2 & 2 & 7 & 3 & 1.75\end{array}$ $\begin{array}{llllllllllllll}22 & .030 & 15 & 6 & 41 & 2 & 64 & 1 & 2 & 1 & 1 & 5 & 2 & 14.75\end{array}$ $\begin{array}{llllllllllllll}20 & .024 & 6 & 14 & 1 & 2 & 23 & 1 & 10 & 1 & 12 & 24 & 1 & -.25\end{array}$

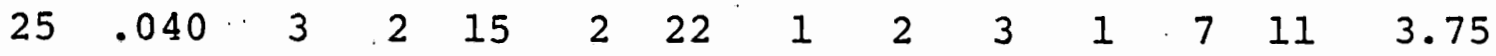

